\title{
The Aldehyde Dehydrogenase ALDH2*2 Allele Exhibits Dominance over ALDH2*1 in Transduced HeLa Cells
}

\author{
Qing Xiao, * Henry Weiner, ${ }^{\ddagger}$ Timothy Johnston, ${ }^{\star}$ and David W. Crabb ${ }^{*}$ \\ *Departments of Medicine and of Biochemistry and Molecular Biology, Indiana University School of Medicine, Indianapolis, Indiana \\ 46202-5121; and ${ }^{\ddagger}$ Department of Biochemistry, Purdue University, Lafayette, Indiana 47907
}

\begin{abstract}
Individuals heterozygous or homozygous for the variant aldehyde dehydrogenase (ALDH2) allele $(A L D H 2 * 2)$, which encodes a protein differing only at residue 487 from the normal protein, have decreased ALDH2 activity in liver extracts and experience cutaneous flushing when they drink alcohol. The mechanism by which this allele exerts its dominant effect is unknown. To study this effect, the human $A L D H 2 * 1$ CDNA was cloned and the $A L D H 2 * 2$ allele was generated by site-directed mutagenesis. These cDNAs were transduced using retroviral vectors into HeLa and CV1 cells, which do not express ALDH2. The normal allele directed synthesis of immunoreactive ALDH2 protein (ALDH2E) with the expected isoelectric point. Extracts of these cells contained increased aldehyde dehydrogenase activity with low $K_{\mathrm{m}}$ for the aldehyde substrate. The $A L D H 2 * 2$ allele directed synthesis of mRNA and immunoreactive protein (ALDH2K), but the protein lacked enzymatic activity. When $A L D H 2 * 1$-expressing cells were transduced with $A L D H 2 * 2$ vectors, both mRNAs were expressed and immunoreactive proteins with isoelectric points ranging between those of ALDH2E and ALDH2K were present, indicating that the subunits formed heteromers. ALDH2 activity in these cells was reduced below that of the parental $A L D H 2 * 1$-expressing cells. Thus, the $A L D H 2 * 2$ allele is sufficient to cause ALDH2 deficiency in vitro. ( $J$. Clin. Invest. 1995. 95:2181-2186.) Key words: enzyme • liver • alcoholism $\cdot$ dominance $\cdot$ protein interactions
\end{abstract}

\section{Introduction}

As many as $50 \%$ of Asians flush when they drink alcohol. This phenotype is usually associated with deficiency in the activity of the mitochondrial aldehyde dehydrogenase (ALDH2) ${ }^{1}(1)$, a tetrameric $\mathrm{NAD}^{+}$-dependent enzyme. This enzyme is responsible for maintaining low concentrations of acetaldehyde in the

Address correspondence to David W. Crabb, Medical Research and Library Building IB 424, 975 W. Walnut Street, Indianapolis, IN 462025121. Phone: 317-274-3122; FAX: 317-274-3106.

Received for publication 20 June 1995 and accepted in revised form 26 July 1995.

1. Abbreviations used in this paper: $\mathrm{ALDH} 2$, mitochondrial aldehyde dehydrogenase; PBS, sodium chloride $150 \mathrm{mM}$, sodium phosphate, 10 $\mathrm{mM}, \mathrm{pH} 7.4$.

J. Clin. Invest.

(C) The American Society for Clinical Investigation, Inc.

0021-9738/95/11/2180/07 \$2.00

Volume 96, November 1995, 2180-2186 liver during ethanol oxidation $(2,3)$. It has a very low $K_{\mathrm{m}}$ for acetaldehyde and other short chain aldehydes $(\sim 1 \mu \mathrm{M})$ and high catalytic efficiency. Activity and gel electrophoretic assays demonstrating the deficiency have been carried out using hair root $(1,4,5)$ and liver biopsy specimens (6) derived from individuals with the flush reaction. To determine the explanation for the deficiency, the enzyme was purified from liver deficient in ALDH2 activity. The inactive enzyme was found to differ from the active enzyme at residue 487 , the result of a glutamate to lysine substitution $(7,8)$. The allele encoding the active enzyme was named $A L D H 2 * 1$ and the inactive variant $A L D H 2 * 2$, and the corresponding protein subunits have been named ALDH2E and ALDH2K, respectively. These genes have been expressed in $E$. coli. The ALDH2K enzyme had markedly altered kinetic properties, with a 150 -fold increase in $K_{\mathrm{m}}$ for $\mathrm{NAD}^{+}$and a $2-10$-fold reduction in $V_{\max }$ compared with the normal enzyme (9).

Biochemical studies generally assumed co-dominant inheritance of the ALDH2 deficient phenotype, and predicted that heterozygotes would have half the usual activity of ALDH2 and perhaps suffer from mild flushing, while homozygotes were predicted to have near complete deficiency and severe flushing. However, family studies performed in the early 1980's indicated that alcohol-induced flushing was transmitted in a dominant manner (10). After the cloning of the $A L D H 2$ gene (11), polymerase chain reaction (PCR)-based genotyping assays demonstrated that the majority of individuals with flushing were heterozygous for the $A L D H 2 * 2$ allele (6). Moreover, ALDH2 deficiency as determined by assays performed on hair roots (4) or liver samples (12) have shown that most ALDH2-deficient samples come from heterozygotes. Quantitation of ALDH activity in liver biopsy samples from individuals genotyped at the $A L D H 2$ locus has indicated that the heterozygotes have perhaps $13 \%$ of the normal enzyme activity (6). Retrospectively, purified enzyme from an ALDH2-deficient liver that was likely to have been heterozygous was reported to contain $15 \%$ of the normal low $K_{\mathrm{m}}$ ALDH2 activity (13). When the intensity of flushing has been correlated with genotype, individuals heterozygous for $A L D H 2 * 2$ have less severe flushing than the $A L D H 2 * 2$ homozygotes (6). Thus, the $A L D H 2 * 2$ allele appears to be incompletely dominant over $A L D H 2 * 1$.

The biochemical explanation for the dominant effect of $A L D H 2 * 2$ is unknown. Coexpression of the two alleles in bacteria generated enzyme with reduced specific activity (Wang, X.-P., Sheikh, S., and Weiner, H., manuscript in preparation). The behavior of these mitochondrial proteins in eukaryotic cells may well differ from that in bacteria, e.g., the variant protein subunit might interact differently with the mitochondrial import system or the chaperonins residing in the matrix space, or be more susceptible to degradation. It was therefore of interest to examine the properties of ALDH2E and ALDH2K when expressed alone or together in cultured cells. We chose to ex- 
press these proteins in HeLa and CV-1 cells, since these cells contain high $K_{\mathrm{m}}$ ALDH activity but no low $K_{\mathrm{m}}$ activity.

\section{Methods}

Materials. Most chemicals, including G418, and supplies were purchased from Sigma Chemical Company (St. Louis, MO). Agarose, trypsin, all restriction endonucleases, DNA modifying enzymes, and all tissue culture media and serum were purchased from GIBCO BRL (New Brunswick, NJ). Hygromycin B was from Boehringer-Mannheim (Indianapolis, IN). All radioisotopes were purchased from Dupont NEN Research Products Inc. (Boston, MA). Oligonucleotides were synthesized by the Biotechnology Core Facility of the Department of Biochemistry and Molecular Biology on an Applied Biosystems model 380B DNA synthesizer. The human liver samples were provided by Drs. William Bosron and T.-K. Li. They were genotyped at the $A L D H 2$ locus using published methods (12).

Cloning of human ALDH2 cDNA. The rat $A L D H 2$ cDNA (14) was used to clone a human $A L D H 2$ cDNA from a human liver $\lambda$ gt 11 cDNA library. Several overlapping clones were recovered; the largest extended from the codon for asparagine 12 to the polyadenylate tail. Since asparagine 12 is contained in the first exon, the cDNA was extended to fulllength using a PCR strategy. Primers spanning bases -43 to -21 in the 5 '-untranslated region and amino acid residues 6 to 11 were used to amplify this region from human genomic DNA. The PCR product was ligated to the cDNA to generate the full length cDNA. To generate $A L D H 2 * 2$ cDNA, the $A L D H 2 * 1$ cDNA was subcloned in Bluescrip and mutated with an oligonucleotide centered on the codon for residue 487 (5' GCATACACTAAAGTGAAAA 3') using the Amersham in vitro mutagenesis kit. The correct sequence of the $A L D H 2 * 1 \mathrm{cDNA}$ and the mutated allele were confirmed by dideoxy sequencing. The human ALDH2 cDNA was $88 \%$ identical to the rat CDNA at the nucleotide level and $95 \%$ identical at the amino acid level.

Construction of retroviral vectors. In preliminary experiments, it was found that the cytomegalovirus (CMV) promoter was a stronger promoter in $\mathrm{HeLa}$ and CV-1 cells than the SV-40 promoter; therefore, the expression vectors were built from the retroviral plasmid pLNCX (15). This vector expresses the G418 resistance gene neo driven by the long terminal repeat. The $A L D H 2 * 1$ and $A L D H 2 * 2 \mathrm{cDNAs}$, containing the mitochondrial leader sequences, were cloned into the HindIII site. These plasmids were named $\mathrm{pLNCE}$ and $\mathrm{pLNCK}$, denoting vectors for expression of ALDH2E and ALDH2K, respectively. To generate cells that expressed both cDNAs, a second vector containing a different selectable marker was constructed by replacing the neo gene with the hygromycin resistance gene from pSV2hyg (16), generating pLHCX. The $A L D H 2 * 2$ cDNA containing the mitochondrial leader and the entire 3 '-untranslated region was cloned into the vector to generate pLHCK. The addition of the $3^{\prime}$-untranslated region permitted differentiation of $A L D H 2 * l$ and $A L D H 2 * 2$ mRNAs in doubly transduced cells based upon size.

Transfection and transduction of tissue-culture cells. The HeLa, CV1, and PA317 packaging cells were grown in minimal essential medium supplemented with $5 \%$ fetal calf serum, $100 \mu \mathrm{g} / \mathrm{ml}$ streptomycin, and 63 $\mu \mathrm{g} / \mathrm{ml}$ penicillin G. The PA317 cells were transfected with the retroviral plasmids by calcium phosphate precipitation (17). Four hours later the cells were exposed to phosphate buffered saline (PBS) containing 15\% glycerol for $3 \mathrm{~min}$. The cells were rinsed twice with PBS and fresh MEM with serum was added. $48 \mathrm{~h}$ after transfection, the medium containing viral particles was recovered, filtered through a $0.2-\mu \mathrm{m}$ filter, and stored frozen. Transduction of HeLa or CV-1 cells was achieved by incubating the cells overnight with $100 \mu \mathrm{l}$ of the viral supernatant in $10 \mathrm{ml}$ of medium containing $4 \mu \mathrm{g} / \mathrm{ml}$ of polybrene. The cells were then selected in medium containing $400 \mu \mathrm{g} / \mathrm{ml}$ of G418 or $200 \mu \mathrm{g} / \mathrm{ml}$ of hygromycin B. Resistant cells were either pooled or individual clones were isolated using cloning rings.

Isolation of RNA and Northern blotting. Total cellular RNA was prepared by extraction with guanidinium thiocyanate (18) and $4 \mathrm{M} \mathrm{LiCl}$ to remove polysaccharides (19). $20 \mu \mathrm{g}$ of total RNA was electrophoresed on a formaldehyde-agarose gel, transferred to a Nytran membrane, prehybridized and hybridized at $42^{\circ} \mathrm{C}$ in buffer containing $50 \%$ formamide, with random hexamer radiolabeled human $A L D H 2$ cDNA. Blots were washed 3 times in 0.1X SSC (SSC is $150 \mathrm{mM}$ sodium chloride, $15 \mathrm{mM}$ sodium citrate, $\mathrm{pH} 7.4$ ) and $0.5 \% \mathrm{SDS}$ at $55^{\circ} \mathrm{C}$ for 20 $\mathrm{min}$. The membranes were exposed to $\mathrm{x}$-ray film with two intensifying screens at $-70^{\circ} \mathrm{C}$. Quantitative analyses were performed by counting the radioactivity in the bands with an AMBIS $\beta$-scanner.

Enzyme analyses. The cells were harvested by scraping into PBS; after centrifuging the cells, the pellet was sonicated in buffer containing $50 \mathrm{mM}$ sodium phosphate, $\mathrm{pH} 7$, with $1 \%$ Triton $\mathrm{X}-100$. ALDH activity was determined in buffer containing $50 \mathrm{mM}$ sodium pyrophosphate, $\mathrm{pH}$ 8.8, $0.1 \mathrm{mM}$ 4-methylpyrazole, $1 \mathrm{mM}$ EDTA, and $2.5 \mathrm{mM} \mathrm{NAD}^{+}$. The rate of formation of NADH was followed by measuring absorbance at $340 \mathrm{~nm}$. After determining a blank rate, the reaction was initiated by adding propionaldehyde at $15 \mu \mathrm{M}$ (low $K_{\mathrm{m}}$ activity) or at $2 \mathrm{mM}$ (total activity). High $K_{\mathrm{m}}$ activity was determined by subtracting the low $K_{\mathrm{m}}$ activity from the total activity.

Isoelectric focusing was performed using $1 \%$ agarose gels containing $0.5 \mathrm{ml}$ of $\mathrm{pH} \mathrm{3-10}$ Ampholines, $1.5 \mathrm{ml}$ of $\mathrm{pH}$ 4-6 Ampholines, and $20 \%$ glycerol in a total volume of $34 \mathrm{ml}$. The anode and cathode buffers were $0.5 \mathrm{M}$ acetic acid and $0.5 \mathrm{M} \mathrm{NaOH}$, respectively. The gel was prefocused at $5 \mathrm{~W}$ for $1 \mathrm{~h}$, then the protein samples were applied and the focusing was continued at $10 \mathrm{~W}$ for $2 \mathrm{~h}$. The gel was then stained for enzyme activity in a solution of $10 \mathrm{mM}$ propionaldehyde, $1 \mathrm{mM}$ $\mathrm{NAD}^{+}, 0.1 \mathrm{mM}$ 4-methylpyrazole, $0.3 \mathrm{mM}$ 3-[4,5-dimethylthiazol-2yl]2,5-diphenyltetrazolium bromide, and $0.14 \mathrm{mM}$ phenazine methosulfate in $50 \mathrm{mM}$ sodium pyrophosphate, $\mathrm{pH} 8.8$. Native ALDH2 was purified from human liver by chromatography of $100,000 \mathrm{~g}$ supernatants on DEAE-cellulose and $\alpha$-cyano-4-hydroxycinnamate-Sepharose affinity columns (20). This preparation showed a single band of 54,000 molecular weight on SDS-PAGE gels stained with Coomassie blue and was used as a positive control for the isoelectric focusing gels and Western blots.

Western blotting. Proteins fractionated in SDS-PAGE gels or by isoelectric focusing were transferred to nitrocellulose filters by electroelution or capillary blotting, respectively. The filters were blocked with PBS containing $0.1 \%$ Tween 20 and 5\% BSA, then incubated with polyclonal antiserum raised against purified bovine liver ALDH2. After washing, the filters were developed by incubating them with ${ }^{125}$ I-labeled protein A. Quantitative Western blotting was performed by generating an internal standard curve with extracts of HeLa CE cells on each gel used to analyze the amount of ALDH protein in the HeLa EK cells. 50, 100 , and $200 \mu \mathrm{g}$ of extract protein from HeLa CE cells were loaded on the gel with either 50 or $100 \mu \mathrm{g}$ of protein from the HeLa EK cells. After isoelectric focusing and blotting, ALDH2 protein was detected with anti-ALDH2 antibody and ${ }^{125}$ I-labeled protein A and quantitated by $\beta$-scanning. The standard curves were linear and the antiserum detected the ALDH2E and ALDH2K proteins equivalently in preliminary studies. The amount of ALDH2 protein in the HeLa EK cells was thereby determined relative to the amount in the parental HeLa CE cells.

\section{Results}

Transduction and expression of $A L D H 2$ isozyme in vitro. The cloned ALDH2 cDNA had the same sequence as found in the human gene reported by Hsu et al. (11) and was the longest clone yet recovered from a liver library. After verifying that the cloned cDNA and the allele created by site-directed mutagenesis had the expected DNA sequence, the cDNAs representing the $A L D H 2 * 1$ and $A L D H 2 * 2$ alleles were subcloned into retroviral vectors under the control of the CMV promoter. Amphotropic retroviruses were generated using the packaging cell line PA317. Viral supernatants were used to transduce the cDNAs into HeLa and CV-1 cells. RNA isolated from the cells 


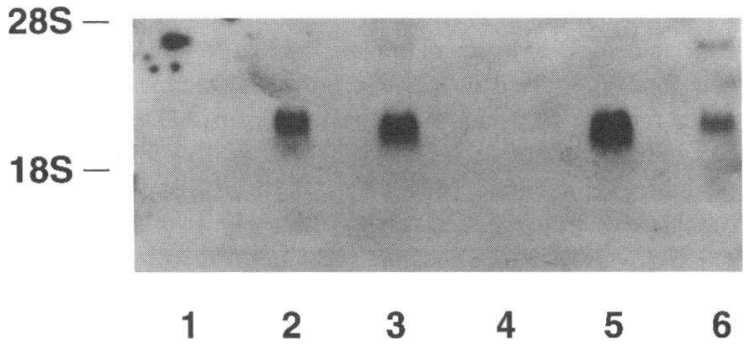

Figure 1. Expression of $A L D H 2 * l$ and $A L D H 2 * 2$ mRNA in virally transduced $\mathrm{HeLa}$ and $\mathrm{CV}-1$ cells. The cells were transduced with pLNCE or pLNCK-derived retroviruses, selected for G418 resistance, then pooled and expanded. Total RNA ( $20 \mu \mathrm{g} / \mathrm{lane}$ ) was Northern blotted and probed with radiolabeled ALDH2 cDNA. Lane 1, parental HeLa cells; lane 2, pLNCE-transduced HeLa cells; lane 3, pLNCK-transduced HeLa cells; lane 4, parental CV-1 cells; lane 5, pLNCE-transduced CV1 cells; lane 6 , pLNCK-transduced $\mathrm{CV}-1$ cells.

was analyzed by Northern blotting (Fig. 1). The parental HeLa cells lacked ALDH2 mRNA, whereas the transduced cells (CE, expressing the $A L D H 2 * 1$ allele, and $\mathrm{CK}$, expressing the $A L D H 2 * 2$ allele) each expressed similar high levels of $A L D H 2$ mRNA. Similar results were obtained with the CV-1 cells, except that the level of $A L D H 2 * 2 \mathrm{mRNA}$ was lower in this pool.

Western blots of the HeLa CE and CK extracts showed that they contained similar levels of ALDH2 protein that was absent from the untransduced HeLa cells (Fig. 2). Both recombinant ALDH2 isozymes migrated at the same size as affinity-purified liver ALDH2, suggesting that the precursor protein encoded by the vector was transported into the mitochondria and the leader sequence processed. Analysis of extracts of these cells showed that the parental HeLa cells contained very low levels of low $K_{\mathrm{m}}$ ALDH activity, although high $K_{\mathrm{m}}$ ALDH activity was present. The cells transduced with the $A L D H 2 * 1$ vector contained ALDH activity when assayed with $15 \mu \mathrm{M}$ propionaldehyde that was absent in the parent cell lines (Table I). This activity is consistent with the kinetic properties of ALDH2. On the other hand, cells transduced with the $A L D H 2 * 2$ cDNA did not have any higher activity of low $K_{\mathrm{m}} \mathrm{ALDH}$ than was detectable in the parental cells. The low $K_{\mathrm{m}}$ activity was confirmed to be due to the presence of ALDH2 by isoelectric focusing of the extracts and staining for ALDH activity (Fig. 3). Only the cells transduced with $A L D H 2 * 1$ vectors had a band of ALDH activity with the appropriate isoelectric point $(\sim 5)$.

One possible explanation for the dominant effect of ALDH2K was that it reduced the stability of tetramers con-

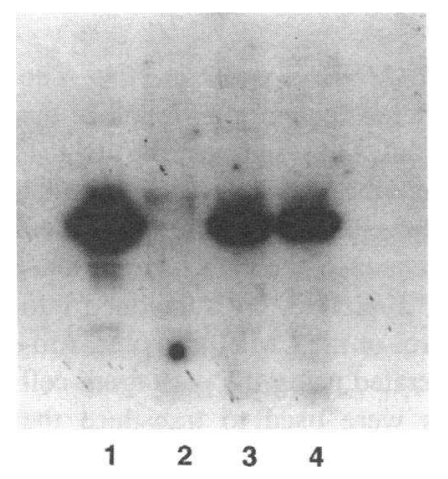

Figure 2. Expression of ALDH2 protein in virally transduced HeLa cell lines. Cell extracts from the HeLa lines shown in Fig. 1 were analyzed by Western blotting for ALDH2 protein. Lane 1 , purified human liver ALDH2 control; lane 2, parental HeLa cells; lane 3, HeLa cells transduced with pLNCE; lane 4 , HeLa cells transduced with pLNCK.
Table I. Aldehyde Dehydrogenase Activity in HeLa and CV-1 Cells Transduced with ALDH2-Expression Retroviruses

\begin{tabular}{lccc}
\hline Cell line & Low Km ALDH & High Km ALDH & $\begin{array}{c}\text { Total } \\
\text { ALDH }\end{array}$ \\
\hline HeLa & $1 \pm 1$ & $17 \pm 1$ & $18 \pm 1$ \\
HeLa CK & $0.1 \pm 0.6$ & $10 \pm 2$ & $11 \pm 1$ \\
HeLa CE & $14 \pm 1$ & $12 \pm 3$ & $26 \pm 4$ \\
CV-1 & $1 \pm 1$ & $19 \pm 1$ & $20 \pm 1$ \\
CV-1 CK & $1 \pm 2$ & $21 \pm 4$ & $23 \pm 5$ \\
CV-1 CE & $20 \pm 1$ & $16 \pm 6$ & $37 \pm 8$ \\
\hline
\end{tabular}

Activities are expressed as $\mathrm{nmol} / \mathrm{min}$ per $\mathrm{mg}$ protein in the cell extract. CE refers to cells transduced with the vector pLNCE and expressing ALDH2E. CK refers to cells transduced with the vector PLNCK and expressing ALDH2K. The activities are the mean \pm standard deviation of determinations made on four different plates of the noted cells.

taining this subunit. Therefore, the half-life of ALDH2K was compared with that of ALDH2E. HeLa CE and HeLa CK cells were exposed to puromycin (at $50 \mu \mathrm{g} / \mathrm{ml}$, a concentration reported to inhibit protein synthesis by over $90 \%$ ) (21) and were harvested at various times for up to $24 \mathrm{~h}$ for analysis of ALDH2 protein levels by Western blotting. ALDH2 protein levels were quantified by $\beta$-scanning of the filters. A least-squares fit of the logarithm of the amount of ALDH2 protein remaining vs time gave a half-life of $26 \mathrm{~h}$ for the ALDH2E protein and $24 \mathrm{~h}$ for ALDH2K. This suggests that the homotetramers are equally stable. This was previously reported for the isozymes expressed in bacteria (9).

Effect of co-expression of $A L D H 2 * 1$ and $A L D H 2 * 2$. To study the interaction between $A L D H 2 * 1$ and $A L D H 2 * 2$, it was necessary to isolate clones of cells expressing high levels of ALDH2E, then transduce them with the ALDH2K vector with a second selectable marker. A clonal line of HeLa cells expressing

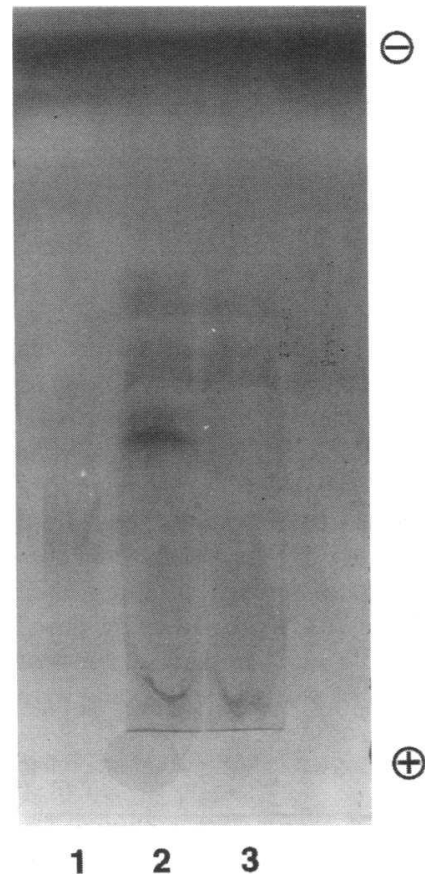

Figure 3. Expression of ALDH2 enzyme activity in HeLa cells. The cell pools shown in Figs. 1 and 2 were analyzed for ALDH2 enzyme on isoelectric focusing gels. The gels were stained for ALDH activity using propionaldehyde and $\mathrm{NAD}^{+}$as substrates. Plus and minus symbols indicate the anodal (acidic) and cathodal (basic) ends of the gel, respectively. Lane 1 , parental HeLa cells; lane 2, HeLa cells transduced with pLNCE; lane 3, HeLa cells transduced with pLNCK. 


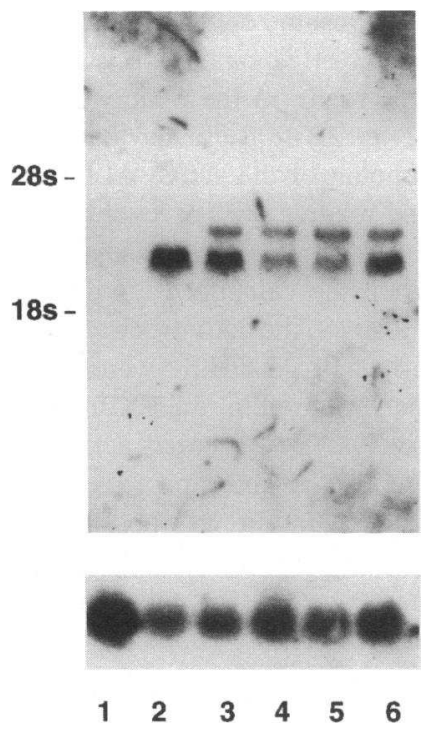

ALDH2E was therefore transduced with the ALDH2K expression virus, and individual clones that were resistant to hygromycin were isolated and tested for expression of ALDH2K mRNA. A Northern blot of RNA from four such clones (denoted by EK2, EK3, EK12, and EK13) is shown in Fig. 4. The higher molecular weight band represents the $A L D H 2 * 2$ mRNA. Relative amounts of the $A L D H 2 * 1$ and $A L D H 2 * 2$ mRNAs were estimated by $\beta$-scanning the filters. The ratio of $A L D H 2 * 2$ mRNA to $A L D H 2 * 1$ mRNA in the different cell lines ranged from $0.63 \pm 0.07$ to $1.02 \pm 0.14$ ( $n=5$ separate preparations of RNA from each of the cell lines). Thus, these cells provide a model for studying the dominance of $A L D H 2 * 2$ over ALDH $2 * 1$.

The isoelectric points of ALDH2 protein in cell extracts and extracts of homozygous and heterozygous human livers were determined by isoelectric focusing followed by Western blotting (Fig. 5). The two homozygous liver samples (lanes 1 and 3) contained ALDH protein with the expected difference in isoelectric points; the heterozygous liver (lane 2) contained immunoreactive protein that spanned these two pIs. The pIs of the retrovirally expressed ALDH2E (lane 4) and ALDH2K (lane 8 ) were identical to those of the corresponding liver ALDHs. This confirmed that the transduced cells correctly processed the nascent ALDH subunits after mitochondrial import, since the leader peptide is highly basic. In the doubly transduced cells (lanes 5-7), there was the appearance of isozyme forms with pIs intermediate between those of ALDH2E and ALDH2K tetramers, as was seen in the liver samples. Liver and cell extracts were also subjected to isoelectric focusing and staining for ALDH activity (Fig. 6). The upper band seen in the liver extracts (lanes 1-3) represented cytosolic ALDH1. In agreement with earlier observations, no ALDH2 activity was detected in the heterozygous (lane 2 ) or homozygous $A L D H 2 * 2$ liver samples (lane 3). The pI for ALDH2E was the same in the ALDH2E-expressing cells (lane 4) as in the liver. Equal amounts of cell protein were loaded in lanes 4 to 8 to permit an estimate of the ALDH2 activity. Variably reduced ALDH2 activity was detected in the three doubly transduced cell lines (lanes 5-7), with no activity in the cells expressing only ALDH2K (lane
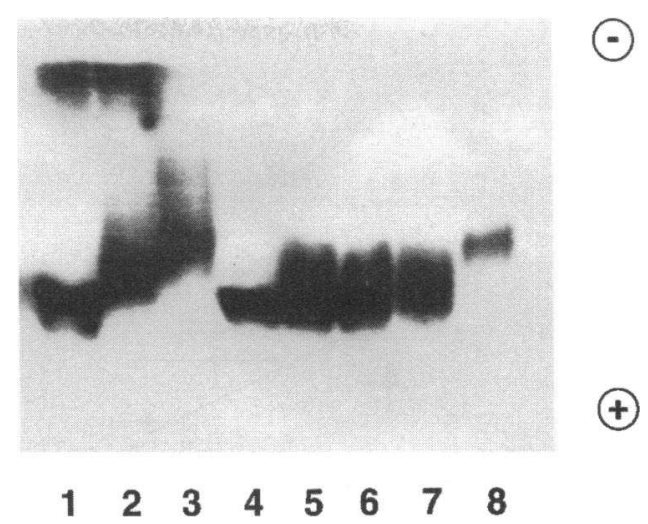

Figure 5. Expression of ALDH2 protein in human livers and doubly transduced HeLa cell lines. Protein extracted from human livers that had been genotyped at the $A L D H 2$ locus or from the cells analyzed in Fig. 4 were separated on isoelectric focusing gels and Western blotted using antibody specific for mitochondrial ALDH2. Lanes 1-3 human liver extracts; lanes 4-8, HeLa cell extracts. Lane $1, A L D H 2 * 1$ homozygote; lane 2, $A L D H 2 * 1 / A L D H 2 * 2$ heterozygote; lane $3, A L D H 2 * 2$ homozygote. Lane 4, HeLa cell expressing only $A L D H 2 * 1$; lanes 5-7, doubly transduced HeLa cell lines: EK13, EK2, EK12, respectively; lane $8, A L D H 2 * 2$ expressing HeLa cells.

8 ). There were faint bands seen migrating slightly cathodal to the major band of ALDH2 activity as had also been seen in the pooled HeLa CE cells (Fig. 3). Thus, introduction of the $A L D H 2 * 2$ expression vector into cells expressing $A L D H 2 * 1$ resulted in a reduction of enzyme activity, indicating that the dominant effect of $A L D H 2 * 2$ occurred in vitro.

To quantify the dominant effect of $A L D H 2 * 2$, enzyme activities of the cell extracts were estimated. The activity of the extracts from each doubly transduced cell line was lower than that of the $A L D H 2 * 1$-expressing cell line from which they were derived, ranging from $22-43 \%$ (mean $34 \%$ ) of that activity (ALDH2E-expressing cells, 22.3 \pm 0.07 ; ALDH2E and $-\mathrm{K}$ co-
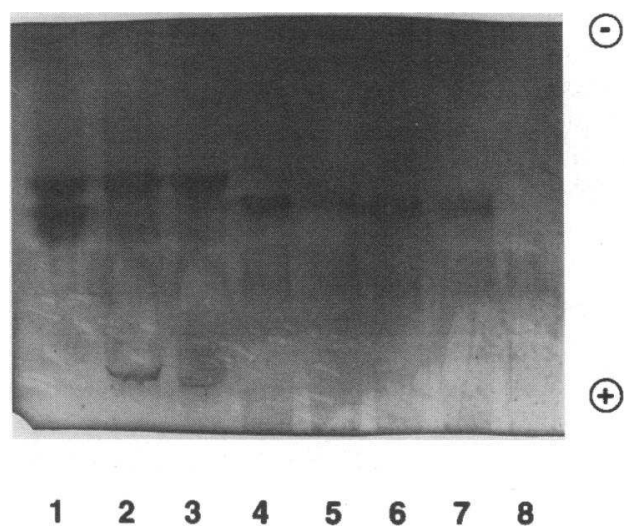

Figure 6. Expression of ALDH2 activity in liver and in doubly transduced HeLa cell lines. The same samples shown in Fig. 5 were analyzed by isoelectric focusing with staining of the gels for ALDH activity using propionaldehyde and $\mathrm{NAD}^{+}$as substrates. The more cathodal band seen in lanes $1-3$, containing liver extracts, represents ALDH1 activity. Enzyme activity was visualized at the pI of the ALDH2E tetramers (compare with lane 1 ), despite the fact that much ALDH2 protein from the doubly transduced cells was distributed more cathodally (compare Fig. 5). 

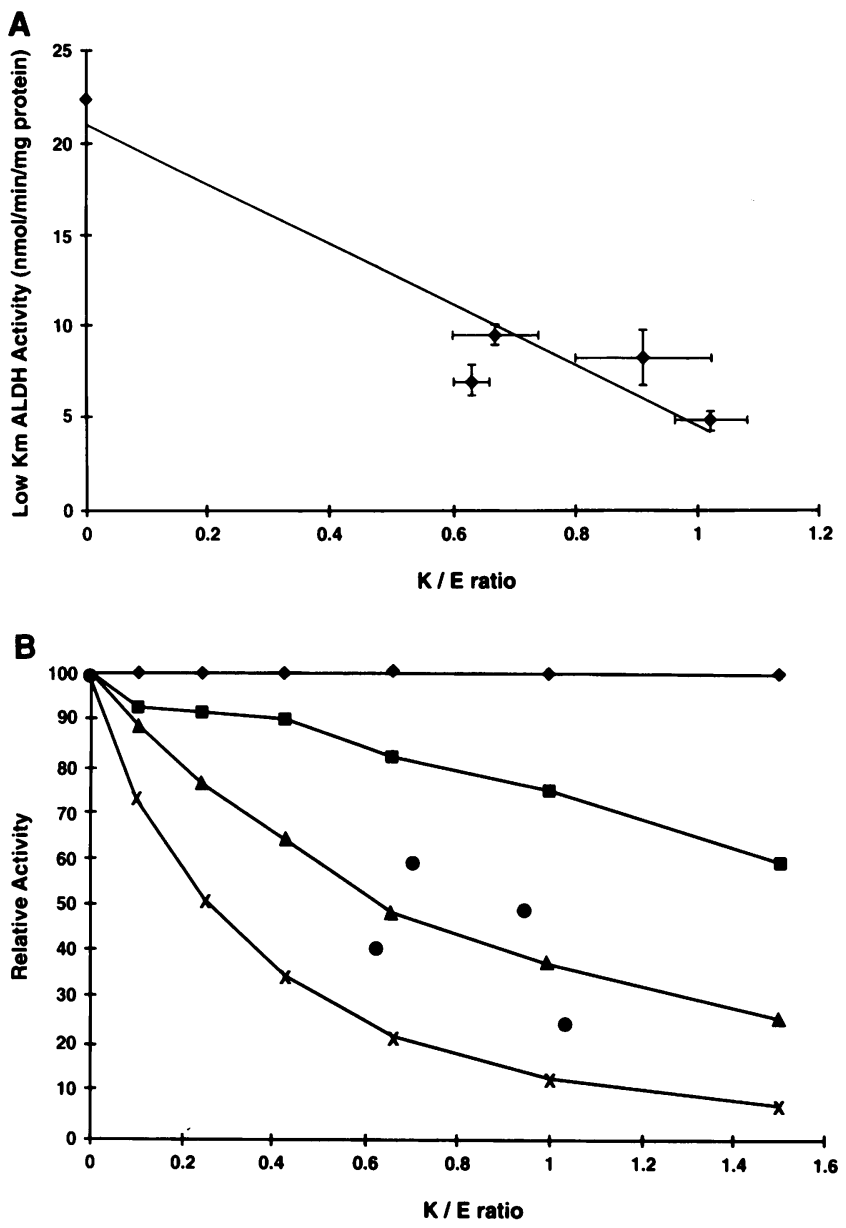

Figure 7. Effect of increasing expression of $A L D H 2 * 2 \mathrm{mRNA}$ on the low $K_{\mathrm{m}}$ ALDH activity of the doubly transduced cell lines. The ratio of the two mRNAs was determined by Northern blots quantified by $\beta$ scanning. Low $K_{\mathrm{m}}$ ALDH activity $(A)$ was expressed as $\mathrm{nmol} / \mathrm{min}$ per $\mathrm{mg}$ cell extract protein. The error bars represent \pm one standard error of the mean for the activity determination or the RNA ratio. The line is a least-squares linear fit of the data. In $B$, relative ALDH activity predicted by the models shown in Table II was calculated for varying ratios of mRNA for ALDH2K and ALDH2E (K/E ratio). ( $\bullet$ ) model 1; ( $\square)$ model 2; ( $\triangle$ ) model 3; and $(\mathrm{X})$ model 4 . Calculation of relative activity in the doubly transduced cells utilized the $\mathrm{K} / \mathrm{E}$ ratio and the total immunoreactive ALDH2 protein estimated by quantitative Western blotting determined for the cell lines (see Results). The experimentally determined relative activities are denoted by $\bullet$.

expressing cell lines: EK13, 9.6 \pm 0.6 ; EK2, 7.1 \pm 0.8 ; EK12, $5.0 \pm 0.5$, and EK3, $8.4 \pm 1.5 \mathrm{nmol} / \mathrm{min} / \mathrm{mg}$ protein, $n=4$ independent determinations for each cell line). These activities were stable over time. Since the Northern blots showed that the relative amounts of ALDH2E and ALDH2K mRNAs expressed in the different cell lines differed, the low $K_{\mathrm{m}}$ ALDH activities were plotted against the ratio of $A L D H 2 * 2$ mRNA/ALDH $2 * 1$ mRNA (Fig. $7 \mathrm{~A}$ ) to determine if there was a relationship between the amount of ALDH2K subunit expressed and the ALDH 2 activity. As the relative amount of $A L D H 2 * 2$ mRNA increased, ALDH2 activity fell progressively.

Although these experiments were designed with the intent that the doubly transduced cells would express the same amount of ALDH2E as the parental cell line, an additional confounding variable was the apparent difference in the absolute amount of
$A L D H 2 * 1$ mRNA in the different cell lines (Fig. 4). To control for this variation we estimated the amount of immunoreactive ALDH2 protein (representing the sum of ALDH2E and ALDH2K proteins) present in the cells by quantitative Western blotting. The amount of ALDH2 protein in the doubly transduced cell lines ranged from 1.2- to 2.1-fold greater than that in the HeLa CE cells, and the amount of the active ALDH2E subunit (calculated by multiplying relative protein level by the relative amount of $A L D H 2 * 1$ mRNA) was in some cases lower than that in the parent cells. When the calculated amount of ALDH2E protein was taken into account, the activities expected in the absence of a dominant effect of ALDH2K were 18.1, $16.3,23.0$, and $16.1 \mathrm{nmol} / \mathrm{min}$ per $\mathrm{mg}$ protein, for EK2, EK3, EK12, and EK13 cells, respectively. The observed activities (given above) were $39,52,22$, and $60 \%$ of the expected activities. From a least-squares fit of these data it was possible to estimate that cells expressing equal amounts of $A L D H 2 * 1$ and $A L D H 2 * 2$ mRNAs (i.e., in heterozygous liver cells) would express $31 \%$ of the predicted ALDH2 activity (not shown).

\section{Discussion}

This study examined the mechanism by which the $A L D H 2 * 2$ allele causes the dominantly inherited ALDH2 deficient phenotype. Previous work with bacterial expression systems indicated that the $A L D H 2 * 2$ allele could direct the synthesis of an enzyme with markedly impaired catalytic function (9), but such systems do not test the ability of the expressed protein to enter and be assembled in the mitochondrial matrix space. We chose to express the two $A L D H 2$ alleles in tissue culture cells that lacked endogenous $A L D H 2 \mathrm{mRNA}$ and protein, and thus had virtually no background signals. Retroviral vectors were utilized because of the efficiency of transduction and high levels of expression of the cDNAs compared with results we had obtained with other expression systems. Initially, pools of HeLa and CV-1 cells transduced with only one of the expression vectors were characterized to test this approach. The results obtained suggest that this system represents a good model to study the interaction between $A L D H 2 * 1$ and $A L D H 2 * 2$. The molecular weights and pIs of the enzymes expressed in the HeLa cells were the same as those detected in the human liver samples, consistent with the removal of the mitochondrial leader. Thus, the subunits were very likely to have been properly transported into the mitochondria and processed. Activity measurements documented that the $A L D H 2 * 1$ allele directed the synthesis of a catalytically active enzyme with low $K_{\mathrm{m}}$ for the aldehyde substrate, whereas the $A L D H 2 * 2$-encoded protein expressed in these cells was not active in the enzyme assay used. However, this assay would not have detected ALDH2K activity if its kinetic properties were the same as those of the bacterially expressed ALDH2K (9) because the $\mathrm{NAD}^{+}$concentration was not high enough. The inability to visualize the ALDH2K form on isoelectric focusing gels stained for activity has also been reported for the bacterially synthesized enzyme (9).

In the HeLa cells initially transduced with each of the vectors, pools of ALDH2E-and ALDH2K-producing cells expressed similiar levels of mRNA and ALDH2 protein, suggesting that the two isozymes had similar stability. The normal and variant proteins also had similar apparent half-lives as determined in protein decay experiments, indicating that the $A L D H 2 * 2$ allele does not encode an overtly unstable protein. Additional pulse-chase experiments would be needed to deter- 


\begin{tabular}{|c|c|c|c|c|c|c|c|c|c|}
\hline \multirow[b]{3}{*}{ Model } & & & ubunit & tion & & \multirow{3}{*}{$\begin{array}{c}\text { Average active } \\
\text { sites per tetramer }\end{array}$} & \multirow{3}{*}{$\begin{array}{l}\text { Total number } \\
\text { of tetramers }\end{array}$} & \multirow{3}{*}{$\begin{array}{l}\text { Total number } \\
\text { of active sites }\end{array}$} & \multirow{3}{*}{$\begin{array}{l}\text { Percent } \\
\text { activity }\end{array}$} \\
\hline & $\begin{array}{c}E_{4} \\
1 / 16\end{array}$ & $\begin{array}{l}E_{3} K \\
4 / 16\end{array}$ & $\begin{array}{l}E_{2} K_{2} \\
6 / 16\end{array}$ & $\begin{array}{l}\mathrm{EK}_{3} \\
4 / 16\end{array}$ & $\begin{array}{c}K_{4} \\
1 / 16\end{array}$ & & & & \\
\hline & \multicolumn{5}{|c|}{ Active sites per tetramer } & & & & \\
\hline 1 & 2 & 2 & 1 & 0 & 0 & $16 / 16$ & $\mathrm{n} / 2$ & $\mathrm{n} / 2$ & 100 \\
\hline 2 & 2 & 1 & 1 & 0 & 0 & $12 / 16$ & $\mathrm{n} / 2$ & $3 n / 8$ & 75 \\
\hline 3 & 2 & 1 & 0 & 0 & 0 & $6 / 16$ & $\mathrm{n} / 2$ & $3 n / 16$ & 37 \\
\hline 4 & 2 & 0 & 0 & 0 & 0 & $2 / 16$ & $\mathrm{n} / 2$ & $\mathrm{n} / 16$ & 12 \\
\hline
\end{tabular}

The subunit composition is that predicted from random association of ALDH2E (E) and ALDH2K (K) subunits. It is assumed that the K subunit is inactive and that its presence interferes with the formation of active sites comprised of $E$ subunits. The models show the predicted activity of enzyme with varying numbers of active sites in the different heterotetramers, based on the assumption that two $E$ subunits are needed to form one active site. Model 1 permits three $\mathrm{E}$ subunits to form two active sites. The average number of active sites/tetramer is calculated as the sum of the number of active sites for a given heterotetramer times the fractional abundance of that form. The total number of tetramers is derived from $n$ ALDH2E subunits plus $n$ ALDH2K subunits divided by four, or $2 n / 4$ or $n / 2$. The total number of active sites is the average number of active sites/ tetramer times the number of tetramers. Percent activity is calculated relative to that of cells expressing one copy of the $A L D H 2 * l$ allele, producing times $\mathrm{n}$ subunits and therefore $\mathrm{n} / 2$ active sites (see text).

mine if there are subtle differences in half-life not detectable by the technique utilized. Thus, the initial studies suggested that the dominant effect of $A L D H 2 * 2$ was likely to be due to interactions between the ALDH2E and ALDH2K proteins at the level of the tetrameric enzyme.

The second phase of these studies examined the effect of transducing the $A L D H 2 * 2$ allele, using a retrovirus with a second selectable marker, into cells expressing $A L D H 2 * 1$. The clones of cells selected from this second round of transduction expressed both alleles' mRNAs at roughly similar levels. The doubly transduced cells produced ALDH2 heterotetramers as shown by the appearance of a broad band of immunoreactive protein spanning the pIs of ALDH2E and ALDH2K, mimicking the electrophoretic behavior of these proteins in the heterozygous human liver sample. The presence of heterotetramers had been suggested by the smear of immunoreactive protein on Western blots of starch gels analyzing human liver extracts (22), but had not previously been directly demonstrated. Furthermore, introduction of $A L D H 2 * 2$ into cells expressing $A L D H 2 * 1$ resulted in a decrease in the low $K_{\mathrm{m}}$ ALDH activity of those cells. Staining of the isoelectric focusing gels for ALDH activity showed that the most active form was found at the most anodal isoelectric point (similar or identical to that of the $(\mathrm{ALDH} 2 \mathrm{E})_{4}$ tetramer). The fainter activity bands migrating cathodal to the major band probably represent posttranslationally modified enzyme (generated by proteolysis or oxidation of sulfhydryl groups) since it was also seen in the cells expressing only the ALDH2E subunit. If only the (ALDH2E) $)_{4}$ tetramer were active in the heterozygous cells, this would suggest that incorporation of a single mutant subunit inactivated the tetramer, as had been speculated in the past $(9,12)$.

However, the activity assays were not consistent with this model. If the heterozygous cells produced equal amounts of the ALDH2 subunits that assembled into tetramers randomly, the abundance of the various combinations of subunits should obey a binomial distribution (Table II). ALDH2 tetramers have been shown to exhibit half of the sites reactivity $(24,25)$, although the location of the active sites within the quaternary structure is not known. Thus, a cell synthesizing n ALDH2E subunits (for example, the HeLa CE cells) will have n/4 tetramers, containing $\mathrm{n} / 2$ active sites. It is possible that in the heterotetramers, two ALDH2E subunits are required to create an active site; practically speaking we can ignore any low activity contributed by the ALDH2K subunits. Table II shows calculations of the average numbers of active sites among the heterotetramers, given various assumptions about the number of active sites per tetramer and the distribution of the different combinations. The predicted ALDH2 activity in the cells was then calculated by multiplying the average number of active sites per tetramer by the number of tetramers present. In cells expressing the two alleles equally, the number of subunits synthesized is $2 \mathrm{n}$, and thus the number of tetramers is $2 n / 4$ or $n / 2$. If the ALDH2K subunits do not interfere with the ALDH2E subunits and the $\mathrm{E}_{3} \mathrm{~K}$ enzyme can form two active sites (model 1 ), the activity is $n / 2$, or $100 \%$ of that calculated for the cells expressing only ALDH2E subunits. We found reduced ALDH2 activity in the doubly transduced cells, and thus there must be some interference by the ALDH2K subunits. In these models, interference was defined as fewer active sites formed in the $E_{2} K_{2}$ or $E_{3} K$ enzymes. We estimated that heterozygous cells would express $31 \%$ of the predicted activity of ALDH2. Model 3, which predicts $37 \%$ of the activity of the parental line, agrees most closely with the experimental findings. Since the cell lines deviated from the assumptions of the model in that they did not express the same amount of $A L D H 2 * 1$ and $A L D H 2 * 2$ mRNA, we also calculated the enzyme activity expected for each model with varying ratios of ALDH2E and ALDH2K subunits and plotted these activities with the relative activity of the double transduced HeLa cell lines (Fig. $7 \mathrm{~B}$ ). The relative activities found in the cell lines were closest to those predicted by model 3 .

The activity predicted to be expressed in liver using these models would be reduced by half, because the acquisition of an $A L D H 2 * 2$ allele is accompanied by the loss of one of the $A L D H 2 * 1$ alleles, with a reduction in the total number of ALDH2E subunits synthesized. For example, using the model proposed for the cells, $A L D H 2 * 1$ homozygotes would synthesize $2 n$ of the ALDH2E subunits, forming $2 n / 4$ or $n / 2$ tetramers, with two active sites each, or $n$ active sites, twice that of model 1 in the cells. Thus, model 3 predicts $18 \%$ residual activity in heterozygous human livers. Two reports of residual ALDH2 
activity in ALDH2-deficient livers found 13\% (6) and 15\% (13) of the normal activity, compatible with the model. However, these studies were performed without the knowledge of additional ALDH isozymes, and may not be definitive. It is not known why residual ALDH activity was visualized on electrophoretic gels for the doubly transduced cells but not in the heterozygous liver sample. Perhaps slightly greater expression of ALDH2E than ALDH2K subunits in the cells (see Fig. 5) resulted in the formation of more of the active ALDH2 tetramers than occurs in heterozygous livers. Alternatively, although the half-lives of subunits appeared similar in the HeLa cells, they may differ in hepatocytes.

It is not clear why the activity suggested to be associated with the $\mathrm{E}_{3} \mathrm{~K}$ enzyme was not readily visualized as a distinct band on gels stained for ALDH activity. Experience with the bacterially synthesized ALDH2K enzyme suggests that, for unknown reasons, it does not stain as expected on gels (9). It is possible that the heterotetramers do not behave electrophoretically as the mean of the individual subunits. This was suggested by the appearance of the immunoblot of the isoelectric focusing gels. We did not observe discrete bands of differing $\mathrm{pI}$ between the locations of the ALDH2E and ALDH2K forms, nor has this been observed with the bacterially synthesized heteromers. This could be explained by subtle differences in the electrophoretic behavior of heterotetramers if subunit interactions are not all equivalent, or by different affinities of the subunits for $\mathrm{NAD}^{+}$, leading to differences in net charge among subpopulations of the protein that could not be resolved by the isoelectric focusing system used here. Posttranslational modifications that alter the isoelectric points could also have occurred. Complete understanding of the dominant effect of $A L D H 2 * 2$ awaits the isolation and kinetic characterization of the individual ALDH2 heterotetramers.

\section{Acknowledgments}

We are indebted to Drs. Ken Cornetta and Rob Hromas (Indiana University School of Medicine) for their assistance in setting up the retroviral system, and Drs. William Bosron and T. $-\mathrm{K}$. Li for the human liver samples. We thank the Molecular Biology Core Laboratory of the Indiana Alcohol Research Center (P50 AA 07611) for performing the genotyping of the human livers.

This work was supported by an American Liver Foundation student research fellowship (to Q. Xiao), AA-K02-00081 and AA-06434 (to D.W. Crabb), and AA-05812 (to H. Weiner).

\section{References}

1. Goedde, H. W., D. P. Agarwal, S. Harada, D. Meier-Tackmann, D. Ruofo, U. Bienzle, A. Kroeger, and L. Hussein. 1983. Population genetic studies of aldehyde dehydrogenase isozyme deficiency and alcohol sensitivity. Am. J. Hum. Genet. 35:769-772.

2. Svanas, G. W., and H. Weiner. 1985. Aldehyde dehydrogenase activity as the rate-limiting factor for acetaldehyde metabolism in rat liver. Arch. Biochem. Biophys. 236(1):36-46.

3. Cao, Q. N., G. -C. Tu, and H. Weiner. 1988. Mitochondria as the primary site of acetaldehyde metabolism in beef and pig liver slices. Alc. Clin. Exp. Res. 12(5):720-724.

4. Goedde, H. W., S. Singh, D. P. Agarwal, G. Fritze, K. Stapel, and Y. K. Paik. 1989. Genotyping of mitochondrial aldehyde dehydrogenase in blood samples using allele-specific oligonucleotides: comparison with phenotyping in hair roots. Hum. Genet. 81:305-307.

5. Harada, S., D. P. Agarwal, and H. W. Goedde. 1981. Aldehyde dehydrogenase deficiency as cause of facial flushing reaction to alcohol in Japanese. Lancet. ii:982.

6. Enomoto, N., S. Takase, M. Yasuhara, and A. Takada. 1991. Acetaldehyde metabolism in different aldehyde dehydrogenase 2 genotypes. Alcoholism: Clin. Exp. Res. 15:141-144.

7. Yoshida, A., I-Y. Huang, and M. Ikawa. 1984. Molecular abnormality of an inactive aldehyde dehydrogenase variant commonly found in Orientals. Proc. Natl. Acad. Sci. USA. 81:258-261.

8. Hempel, J., R. Kaiser, and H. Jornvall. 1984. Human liver mitochondrial aldehyde dehydrogenase: a C-terminal segment positions and defines the structure corresponding to the one reported to differ in the Oriental enzyme variant. FEBS Lett. 173:367-373.

9. Farres, J., X. Wang, K. Takahashi, S. J. Cunningham, T. T. Wang, and H. Weiner. 1994. Effects of changing glutamate 487 to lysine in rat and human liver mitochondrial aldehyde dehydrogenase. J. Biol. Chem. 269:13854-13860.

10. Schwitters, S. Y., R. C. Johnson, S. B. Johnson, and F. M. Ahern. 1982. Familial resemblances in flushing following alcohol use. Behavior Genetics. $12: 349-352$.

11. Hsu, L. C., R. E. Bendel, and A. Yoshida. 1988. Genomic structure of the human mitochondrial aldehyde dehydrogenase gene. Genomics. 2:57-65.

12. Crabb, D. W., H. J. Edenberg, W. F. Bosron, and T-K. Li. 1989. Genotypes for aldehyde dehydrogenase deficiency and alcohol sensitivity. The inactive ALDH2*2 allele is dominant. J. Clin. Invest. 83:314-316.

13. Ferencz-Biro, K., and R. Pietruszko. 1984. Human aldehyde dehydrogenase: catalytic activity in Oriental liver. Biochem. Biophys. Res. Commun. 118:97102.

14. Farres, J., K. -L. Guan, and H. Weiner. 1989. Primary structures of rat and bovine liver mitochondrial aldehyde dehydrogenases deduced from cDNA sequences. Eur. J. Biochem. 180:67-74.

15. Miller, A. D., and G. J. Rosman. 1989. Improved retroviral vectors for gene transfer and expression. Biotechniques. 7:980-990.

16. Gritz, L., and J. Davies. 1983. Plasmid encoded hygromycin B resistance: the sequence of hygromycin B phosphotransferase gene and its expression in Escherichia coli and Saccharomyces cerevisiae. Gene. 25:179-188.

17. Graham, F. L., and A. J. Van Der Eb. 1973. A new technique for the assay of infectivity of human adenovirus 5 DNA. Virology. 52:456-467.

18. Chomczynski, P., and N. Sacchi. 1987. Single-step method of RNA isolation by acid guanidinium thiocyanate-phenol-chloroform extraction. Anal. Biochem. 162:156-159.

19. Puissant, C., and L-M. Houdebine. 1990. An improvement of the singlestep method of RNA isolation by acid guanidinium thiocyanate-phenol-chloroform extraction. Biotechniques. 8:148-149.

20. Poole, R. C., and A. P. Halestrap. 1989. Purification of aldehyde dehydrogenase from rat liver mitochondria by alpha-cyanocinnamate affinity chromatography. Biochem. J. 259:105-110.

21. Boren, J., L. Graham, M. Wettesten, J. Scott, A. White, and S. O. Olofsson 1992. The assembly and secretion of ApoB 100-containing lipoproteins in HepG2 cells. ApoB 100 is cotranslationally integrated into lipoproteins. J. Biol. Chem. 267:9858-9867.

22. Johnson, C. T., W. F. Bosron, C. A. Harden, and T-K. Li. 1987. Purification of human liver aldehyde dehydrogenase by high-performance liquid chromatography and identification of isoenzymes by immunoblotting. Alcoholism: Clin. Exp. Res. 11:60-65. 